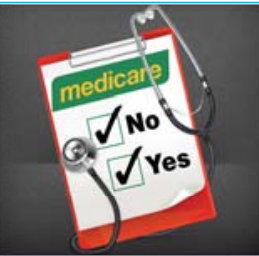

\title{
Who gets the care in Medicare?
}

\section{Medicare has improved equity of use of some but not all health care services}

in Australia

Mark F Harris MB BS, FRACGP, MD, Director and Professor of General Practice

Centre for Primary Health Care and Equity, University of New South Wales, Sydney, NSW.

m.f.harris@unsw.edu.au doi: 10.5694/mjal2.11532

Online first 26/11/12

Research p 625 here is considerable evidence for disparities in health and risk factors for ill health of Australians on the basis of socioeconomic status. ${ }^{1}$ While the health of the population is improving overall (eg, increasing life expectancy, reduced cardiovascular mortality), these disparities are remaining or even widening. ${ }^{2}$ As we move from higher to lower socioeconomic status, many markers of health and disability become progressively worse - what has been described as the socioeconomic gradient. $^{3}$

The socioeconomic gradient in health is influenced by a broad range of social determinants. Use of health care is only one factor that contributes to health. However, timely use of health care does contribute to health and reduce disability - something that is evident in countries where access is extremely poor. ${ }^{4}$ This is of course strongly influenced by the affordability of health care to patients, along with other factors such as workforce availability. The latter is a major factor responsible for reduced Medicare spending in rural and remote areas.

Universal health insurance was introduced in Australia in 1975 (initially called Medibank and later reintroduced as Medicare), financed through the tax system. ${ }^{5}$ This was designed to make health insurance fairer and more affordable for all Australians, avoiding patients having to face catastrophic health expenditure. There is increasing 
evidence that Medicare has been largely successful in reducing inequity in the use of primary medical care, with low socioeconomic groups using general practice and public hospital services more frequently than high socioeconomic groups (as is appropriate to need). ${ }^{6}$ Of course this is a simplistic picture because workforce distribution and other factors cause more subtle inequities in access to quality care - such as reduced time in consultations or reduced availability after hours in disadvantaged areas. ${ }^{7}$ Also, inequities remain for low socioeconomic groups in remote rural areas with lower bulk-billing rates (although there is evidence that these have reduced in recent times in association with government incentives). ${ }^{8}$ However, the overall effect of Medicare has been to reduce differentials in use of primary health care and we should acknowledge and protect these achievements at the same time as seeking to make further improvements.

The picture is far less positive for specialist care and dental care. Although medical specialist care including imaging is reimbursed through Medicare, the average size of co-payments over and above the Medicare rebate has increased over the past 20 years. Patients on low incomes are less likely to see a specialist than those with higher incomes. ${ }^{9}$ Over the past 30 years, access to dental care has consistently been in inverse proportion to socioeconomic disadvantage. ${ }^{10}$ This is despite some investment in state-run public dental services. Inequities are exacerbated by the workforce distribution, with worse access in rural areas.

More recently, we have seen changes to the type of services funded under Medicare. Beginning in 1999, Medicare items began to recognise the need to fund planned care for patients with long-term conditions including mental illness. This provided funding for general practitioners to assess patient needs and plan care for a year. This has become the gateway for patients with chronic disease to access funding for a limited number of allied health services. There is also increased funding for psychological services through Medicare. More recently, dental services were added to chronic care initiatives.

Overall it appears that GP care plans have been provided equitably, with higher rates in low socioeconomic groups who are at higher risk of chronic disease and multiple comorbid conditions. ${ }^{11}$ An evaluation of psychological services provided under Medicare suggested that these were inequitably distributed in socioeconomic and geographic terms. ${ }^{12} \mathrm{~A}$ major reason for this was seen to be the geographic distribution of psychologists and demand factors. This was used as a reason for reducing funding through Medicare in favour of more directed funding through Divisions of General Practice.

There has been less evidence of equity of access to allied health services, with the limited research suggesting that there are disparities between states and for specific populations in high need (eg, Indigenous people). ${ }^{13}$

There is some evidence that dental care provided under the Chronic Disease Dental Scheme is more equitable, as described by Knott and colleagues in this issue of the Journal. ${ }^{14}$ However, while it has advantaged low socioeconomic groups, the linking of dental care to chronic disease has meant that other patients in high need but without chronic disease did not have access to the scheme. Another criticism has been that the scheme has not always provided the most needed care, with less urgent crown and bridge work being performed under the scheme.

This scheme has now been replaced with a package that includes basic dental services for children, funding for adult public dental services through the states (often this involves state dental services providing an initial assessment and then issuing vouchers for specific services in the private sector) and some targeted funding for dental infrastructure in outer urban, regional and rural areas. ${ }^{15}$ It is unclear what the net effects of this will be. Certainly, Medicare coverage for adults with chronic disease is reduced under this change. We will have to see how this change will affect equity of access to dental care overall.

We should thus celebrate and protect the contribution of Medicare (and other measures such as the Pharmaceutical Benefits Scheme) to improved access to primary care in Australia. However, major challenges remain, especially in ensuring equity of access to medical specialist, psychological and dental care. Further research is needed to uncover the reasons for these inequities, especially the relative contribution of the funding mechanism and other factors such as workforce supply.

\section{Competing interests: No relevant disclosures.}

Provenance: Commissioned; externally peer reviewed.

1 Australian Institute of Health and Welfare. Australia's health 2010. Canberra: AIHW, 2010. (AlHW Cat. No. AUS 122; Australia's Health Series No. 12.) http:// www.aihw.gov.au/publication-detail/?id=6442468376 (accessed Oct 2012).

2 Australian Bureau of Statistics. National Health Survey: summary of results, 2007-2008 (Reissue). Canberra: ABS, 2009. (ABS Cat. No 4364.0.) http:// www.abs.gov.au (accessed Oct 2012).

3 Glover JD, Hetzel DM, Tennant SK. The socioeconomic gradient and chronic illness and associated risk factors in Australia. Aust New Zealand Health Policy 2004; 1: 8.

4 World Health Organization. The world health report 2008 - primary health care (now more than ever). Geneva: WHO, 2009. http://www.who.int/whr/ 2008/en/ (accessed Oct 2012).

5 Deeble JS. Unscrambling the omelet: public and private health care financing in Australia. In: McLachlan G, Maynard A, editors. A public/private mix for health: the relevance and effects of change. London: Nuffield Provincial Hospitals Trust, 1982: 425-465.

6 Hajizadeh M, Connelly LB, Butler JRG. Health policy and horizontal inequities of health-care utilization in Australia: 1983-2005. Appl Econ Lett 2012; 19: $1765-1775$.

7 Furler JS, Harris E, Chondros P, et al. The inverse care law revisited: impact of disadvantaged location on accessing longer GP consultation times. Med J Aust 2002; 177: 80-83.

8 Dolja-Gore X, Byles JE, Loxton DJ, et al. Increased bulk-billing for general practice consultations in regional and remote areas, 2002-2008. Med J Aust 2011; 195: 203-204.

9 Van Doorslaer E, Clarke P, Savage E, Hall J. Horizontal inequities in Australia's mixed public/private health care system. Health Policy 2008; 86: 97-108.

10 FitzGerald EM, Cunich M, Clarke PM. Changes in inequalities of access to dental care in Australia 1977-2005. Aust Econ Rev 2011; 44: 153-166.

11 Pegram R, Daniel J, Harris M, et al, editors. General practice in Australia 2004. Canberra: Department of Health and Ageing, 2005.

12 Pirkis J, Harris M, Hall W, Ftanou M. Evaluation of the Better Access to Psychiatrists, Psychologists and General Practitioners through the Medicare Benefits Schedule Initiative: summative evaluation final report. Melbourne: Centre for Health Policy, Programs and Economics, University of Melbourne, 2001. http://www.health.gov.au/internet/main/publishing.nsf/Content/ E31B4C0752BAE99FCA25784C0078BFCD/\$File/sum.pdf (accessed Oct 2012).

13 Cant RP, Foster MM. Investing in big ideas: utilisation and cost of Medicare Allied Health services in Australia under the Chronic Disease Management initiative in primary care. Aust Health Rev 2011; 35: 468-474.

14 Knott RJ, Cass A, Heeley EL, et al. How fair is Medicare? The income-related distribution of Medicare benefits with special focus on chronic care items. Med J Aust 2012; 197: 625-630.

15 Department of Health and Ageing. Dental Reform. http://www.health.gov.au/ internet/main/publishing.nsf/Content/dentalreform (accessed Oct 2012). 